\title{
Why Is the Unemployment Rate So High at Full Employment?
}

The outstanding PROBlem of contemporary macroeconomic policy in the United States is the unfavorable trade-off that exists between unemployment and inflation. Many economists have studied this phenomenon in detail, ${ }^{1}$ and there is practically universal agreement that low unemployment rates imply high rates of wage and price inflation, or, equivalently, wage and price stability requires a high rate of unemployment. In short, the Phillips curve has an unfavorable location in the unemploymentinflation diagram, passing far above and to the right of the point of low unemployment and wage stability. There are many interesting ways to examine this problem; my purpose in this paper is to study it only in the way suggested by the title. That is, I will look into the nature of the unemployment that remains when labor markets are reasonably tight and the economy seems to be at full employment. Most of my data are observations on individuals, collected in a variety of surveys, rather than macroeconomic aggregates.

* This paper draws on research supported by a grant from the Manpower Administration, U.S. Department of Labor, under provisions of the Manpower Development and Training Act of 1962. Earlier work was supported by the Office of Economic Opportunity. The author is solely responsible for the opinions expressed.

1. In particular, see Robert J. Gordon, "The Recent Acceleration of Inflation and Its Lessons for the Future," Brookings Papers on Economic Activity (1:1970), pp. 8-41; and George L. Perry, "Changing Labor Markets and Inflation," Brookings Papers on Economic Activity (3:1970), pp. 411-41. 
Throughout the paper, I will occasionally refer to the notion of the equilibrium level of unemployment. I use this term more or less synonymously with "full employment unemployment" to mean the level that, if maintained permanently, would produce a steady rate of inflation of 3 or 4 percent per year. ${ }^{2}$ Most economists agree that this is somewhere between 4 and 5 percent unemployment. ${ }^{3}$ Further, to forestall misunderstanding, I should say something about the relevance of my study to contemporary macroeconomic problems. Nothing in this paper directly concerns the state of the economy at the end of 1970 with 6.0 percent unemployment, surely above the equilibrium level at current rates of inflation of 4 to 6 percent per year. Rather, the paper concerns current problems of macroeconomic policy in the sense that it suggests why it would not be possible to reach and maintain, in a year or two, a level of unemployment of, say, 3 percent, through the application of even the most intelligently conceived fiscal and monetary policy.

The body of the paper begins with a discussion of the problem of defining and measuring unemployment. Definition derives from theory. In this case the theory underlying most macroeconomic thinking about unemployment is that of Keynes. Keynes believed that a certain level of frictional unemployment was characteristic of all labor markets, but that, in addition, involuntary unemployment could arise when a condition of disequilibrium existed in labor markets, with supply exceeding demand. Involuntary unemployment, then, is the difference between supply and demand. Further, as Keynes emphasized, the forces causing movement toward aggregate equilibrium in the labor market are weak, so unemployment will persist in the absence of active policy-indeed, even in its presence, as this paper seeks to explore.

Keynes proposed an elaborate and frequently misunderstood definition

2. There is nothing special about this rate of inflation. In general, the optimal rate of inflation depends on the relative social costs of unemployment and inflation. This rate is merely illustrative and does not play an important role in what follows.

3. Milton Friedman, Edmund Phelps, and a number of other economists have argued that the equilibrium rate defined in this way is a fixed, "natural" rate, independent of the steady-state rate of inflation. If so, my definition of full employment unemployment is unambiguous; otherwise, it depends, probably not very sensitively, on the rate of inflation. See, for example, Milton Friedman, "The Role of Monetary Policy," in American Economic Review, Vol. 58 (March 1968), pp. 1-17; and Edmund S. Phelps, "The New Microeconomics in Inflation and Employment Theory," in American Economic Association, Papers and Proceedings of the Eighty-first Annual Meeting, 1968 (American Economic Review, Vol. 59, May 1969), pp. 147-60. 
of involuntary unemployment to accompany his theory. For my purposes, his definition can be put in the following simple way: A person is unemployed if he offers his labor at its market price but is unable to find a buyer. Keynes explicitly distinguished this kind of unemployment from frictional unemployment, which he believed arose in the normal operation of the labor market. From the start, government agencies have had to use a single definition to measure all unemployment, and problems of measurement have caused the definition used in the United States to evolve toward one more appropriate for measuring frictional unemployment. The next section discusses the implications of this change, and concludes with a warning about the unreliability of all data on unemployment. The reader will note that the warning is largely unheeded in the rest of the paper. Unemployment is too important a problem to be ignored by empirical economists on the grounds of unsatisfactory data.

A basic theme of this paper is that the Keynesian dichotomy between frictional and involuntary unemployment, however useful to the study of cyclical contractions in aggregate demand, for which it was originally formulated, is not helpful in examining the problem of unemployment at full employment. This theme is developed in the last three sections. Before starting that discussion, however, I examine the data on unemployment from a different point of view, without attempting to distinguish between frictional and involuntary components, or, indeed, between any measures of normal and abnormal unemployment. This point of view holds that the persistence of unemployment at full employment may be explained in part by the fact that a few geographical regions contribute a disproportionate amount of unemployment when the economy as a whole is at full employment. Structural imbalances of this sort are the basis of one important school of thought about Phillips curves. Data on unemployment by city seem to confirm the hypothesis that geographic variation in unemployment is important, and, moreover, they suggest that these differentials are persistent. The discussion of this observation anticipates some of what is said later about turnover in the labor force.

There follows a discussion of how one might classify the various kinds of unemployment that exist at full employment. It would be useful to separate total unemployment into a normal component, about which policy makers should not worry, and an abnormal component, about which they should. The normal component would exist even in an efficiently organized labor market, and typically the experience of unemploy- 
ment would be brief and infrequent for any single worker. The traditional distinction between frictional and involuntary unemployment appears to suggest that the frictional component is normal and the involuntary component is abnormal. However, there is no satisfactory practical way to measure the two components. A crude approach is to suppose that individuals who find jobs after looking for a certain period constitute the frictionally unemployed, while those who remain unemployed for long periods constitute the involuntarily unemployed. That is, one might measure abnormal unemployment as the amount of chronic unemployment. The notion of "hard-core" unemployment seems to embody the view that a substantial number of individuals are permanently out of work, and that the main social problem of unemployment involves these individuals rather than those who are unemployed but find jobs within a few weeks or months. Confronted with the data on the duration of unemployment, this view suffers rather badly. At full employment, very few individuals remain unemployed for more than a few months. Further, it does not appear that there are large numbers of individuals who are actually chronically unemployed but are reported as out of the labor force in the official data.

If unemployment is pathologically high at full employment, then, it must be that some part of frictional unemployment is abnormal. The exploration of this hypothesis is the topic of the last two sections. First I calculate a theoretical full employment rate of unemployment starting from the assumption that normal turnover-changes from school to job and from job to job-accounts for all unemployment. For white males, the actual rate in a month of full employment is slightly below the hypothetical rate, but for blacks and for females the rates are far above it. From this I conclude that turnover is higher than it ought to be if labor markets are working properly, and that not every change in job constitutes normal advance of a career or normal movement from an industry with declining demand to one with increasing demand. The final section looks into the differences between white males and others in terms of their pattern of wages over age groups. It concludes with some evidence on differentials in unemployment among members of the same sex-race group.

With the existing data it does not seem possible to distinguish sharply between the normal and abnormal components of unemployment. No rule for doing so is offered in this paper. The evidence presented here does seem to suggest the following answer to the somewhat paradoxical question posed in the title of the paper: Unemployment is high at full employment 
both because (1) normal unemployment remains high-the natural flow of workers through the labor market is high; and (2) there is an additional component of abnormal unemployment-members of some groups in the labor force do not follow definite careers but change frequently and erratically from one job to another, experiencing unemployment with most changes.

\section{Defining and Measuring Unemployment}

The problem of defining and measuring unemployment has concerned economists since the Great Depression, when it became clear that unemployment was the single most important indicator of economic distress in an industrial economy. The simple disequilibrium view has dominated thinking about the definition of unemployment since then, even in periods like the late 1960s when aggregate excess supply plainly did not exist in the labor market. The major debate of the late 1950s and early 1960s between advocates of the structural and deficient-aggregate-demand views of the prevailing high rates of unemployment was carried out largely within the definition implicit in the disequilibrium theory. According to that definition, unemployment is the difference between the supply and demand for labor at the prevailing rigid wage. An unemployed person is one who is willing to work at a wage currently being paid to other individuals like himself, but who finds no job available. This definition is purely subjective - there is no objective way to distinguish between an individual who is unemployed and one who has decided not to work.

Early attempts to measure unemployment involved simply asking a representative group of individuals whether they were working, and if not, whether they thought they were unemployed. Doubts about this procedure led to the use of a more behavioral definition. The celebrated report of the Gordon Committee, Measuring Employment and Unemployment, laid down as its first general rule that "each concept should correspond to objectively measurable phenomena and should depend as little as possible on personal opinion or subjective attitudes." 4 The objectively measurable phenomenon underlying the measure of unemployment currently in use in the United

4. President's Committee To Appraise Employment and Unemployment Statistics, Measuring Employment and Unemployment (1962), p. 43. 
States is "specific job-seeking activity within the past four weeks." It would be natural to expect that many individuals who were unemployed in the sense of the original definition would not be recorded as unemployed according to this criterion. The disequilibrium theory of unemployment does not suggest that a rational person would continue to search for work after discovering the existence of excess supply for labor.

The Gordon Committee recommended that the household survey be extended to identify "discouraged workers" who had stopped looking for work. The extension was carried out starting in January 1967, and quarterly data have been published since December 1969. They show that there are very few discouraged workers when the labor market is tight. In the second quarter of 1969, there were 149,000 men and 386,000 women who had not looked for work in the past four weeks who still desired it but reported that they were unable to find it. By contrast, there were $1,254,000$ men and 1,288,000 women unemployed in April 1969 according to the official definition. These results suggest that no major error is caused by using a strict definition of unemployment in terms of recent activity in seeking jobs. I will argue later in the paper that there is a different sense in which many individuals out of the labor force might be classified as unemployed.

Evidence from the monthly household survey suggests, however, that even the new definition measures partly the individual's state of mind, or more precisely, the opinion of the respondent (generally, the wife) about the state of mind of the adults in the household. In any month, the sample contains eight groups distinguished by the number of times the household has appeared previously in the survey. Each household included in the sample appears for four consecutive months, is dropped for eight months, and then appears again for four consecutive months. Each of these rotation groups is drawn by the same carefully arranged sampling plan, and, except for random fluctuations, each group should give the same estimates of total unemployment when properly inflated. This turns out to be far from the case. A peculiar and persistent phenomenon known as rotation group bias appears in the data on unemployment. The following data ${ }^{6}$ illustrate the

5. U.S. Bureau of Labor Statistics and U.S. Bureau of the Census, "Concepts and Methods Used in Manpower Statistics from the Current Population Survey," BLS Report 313 and Census Bureau, Current Population Reports, Series P-23, No. 22 (1967), p. 5.

6. These data come from unpublished computer tabulations of the U.S. Bureau of Labor Statistics. 
problem; they show unemployment by rotation group as a percent of the average for all rotation groups in February 1970.

\begin{tabular}{cccccccc}
\multicolumn{8}{c}{ Month in the survey } \\
1 & 2 & 3 & 4 & 5 & 6 & 7 & 8 \\
114.2 & 91.3 & 110.8 & 101.8 & 100.8 & 91.4 & 93.2 & 96.5
\end{tabular}

Households tend generally to report higher unemployment if they have recently been added to the sample, except for the second group. The first four rotation groups account for well over half of the unemployment reported in the whole sample. Apparently the act of interviewing one member of a household for the first time has a perceptible effect on the likelihood that one or more members of the family will be reported as unemployed. Either the initial interview causes individuals who were previously looking for work to leave the labor force, or it induces a change in the respondent's or the subject's opinion about the latter's status in the labor force. The second seems the more likely explanation, and suggests that the official measure of unemployment is rather more subjective than might appear from its description. My results, and those of others studying unemployment, should be interpreted with this in mind. In particular, some of the differences in reported unemployment rates among demographic groups may arise purely because of differences in the meaning attributed to the questions in the household survey. It seems unlikely, however, that any large fraction of the sizable difference between, for example, blacks and whites can be explained in this way.

\section{Geographical Variations in Unemployment}

A conventional view among economists about the persistence of unemployment when the economy is at full employment can be put in the following way: There are many different labor markets, distinguished by geographical location and the skills and other characteristics of the participants. Workers cannot move easily from one market to another since it is expensive to move their households or to acquire a new set of skills. At any point in time, some of the markets will be in equilibrium (involving, of course, frictional unemployment, as noted earlier), some will have 
shortages of workers, and some will have excess workers and hence unemployment. If demand begins to expand in all of the markets more or less uniformly, then the labor shortages will become more severe, and some of the markets that had unemployment before will develop shortages themselves. But even if demand rises to the point that shortages are widespread and wages are rising briskly, so that the economy appears to be at full employment, some markets will still have unemployment. To put it another way, there are bottlenecks that prevent output from rising enough to reduce unemployment to minimal frictional levels in every market.

Two forces tend to bring about the gradual elimination of the kind of imbalance just described. First, in the longer run workers may move from a market with excess labor supply to one with a labor shortage, either by relocating geographically or by offering a different skill. Second, the wage level may fall (at least relative to other wages) in markets with unemployment, stimulating demand for labor in those markets, and eventually putting the unemployed to work. Economists continue to disagree about the strength of these two equilibrating forces. Pessimists believe that they are so weak that there are markets-for unskilled workers in depressed regions, for example-where unemployment above frictional levels is virtually permanent in spite of the most energetic expansionary policy for aggregate demand. This is the hypothesis of structural unemployment. ${ }^{7}$ A more optimistic view holds that under conditions of stable demand, the equilibrating forces of labor mobility and changes in relative wages could eventually eliminate unemployment and labor shortage in every labor market, but that the process is thwarted by continual shifts in the composition of demand. According to this view, high unemployment at full employment is simply a reflection of the fact that, at any moment in time, some unlucky workers will find themselves in markets where the demand for labor has just fallen relative to the supply, creating unemployment.

I propose to examine these hypotheses in terms of the conditions in the labor markets of twelve large cities in the United States, without trying to distinguish the various markets in each city for skills of different types. By any measure of unemployment, there are substantial variations among cities in their rates of unemployment. Table 1 presents estimates prepared for the Manpower Administration of average annual rates of unemploy-

7. My characterization of the problem of structural unemployment follows Robert M. Solow, The Nature and Sources of Unemployment in the United States (Stockholm: Almqvist and Wiksell, 1964). 
Table 1. Unemployment Rates in Twelve Cities, Annual Averages, 1965-69

Percenta

\begin{tabular}{lccccc}
\hline \multicolumn{1}{c}{ City } & 1965 & 1966 & 1967 & 1968 & 1969 \\
\hline Baltimore & 3.8 & 2.9 & 2.8 & 2.9 & 2.8 \\
Chicago & 3.0 & 2.6 & 2.7 & 2.7 & 2.5 \\
Cleveland & 3.1 & 2.6 & 2.8 & 2.5 & 2.3 \\
Detroit & 3.5 & 3.3 & 4.2 & 3.9 & 3.7 \\
Houston & 3.2 & 2.4 & 2.1 & 1.9 & 2.2 \\
Los Angeles & 5.7 & 4.5 & 4.5 & 4.2 & 4.1 \\
New York & 4.5 & 4.2 & 3.7 & 3.3 & 3.2 \\
Philadelphia & 4.3 & 3.3 & 3.2 & 3.1 & 3.0 \\
Pittsburgh & 3.6 & 3.0 & 3.1 & 2.8 & 2.5 \\
St. Louis & 3.5 & 3.3 & 3.4 & 3.5 & 3.5 \\
San Francisco & 5.0 & 4.4 & 4.4 & 4.0 & 3.9 \\
Washington, D.C. & 2.2 & 2.4 & 2.3 & 2.2 & 2.2 \\
\hline
\end{tabular}

Source: Manpower Report of the President, March 1970, Prepared by the U.S. Department of Labor (1970), Table D-8, pp. 284-86.

a. Annual averages of total unemployment as percent of total work force.

ment for the twelve cities. ${ }^{8}$ In 1965 , a year of 4.5 percent national unemployment, the highest rate was considerably more than twice the lowest rate. Four years later, in 1969, when the national unemployment rate was 3.5 percent, the rates still show a great deal of dispersion; further, there seems to have been a general tendency for the rates to fall more or less uniformly.

These data seem to support the conventional view that a few markets with excess supply of labor contribute disproportionately to the national unemployment rate. Moreover, they seem to support the hypothesis of long-term structural unemployment. They show little evidence that the equilibrating forces have much effect over the four-year span of the data. The scatter diagram of Figure 1 demonstrates this graphically. Except for Detroit and St. Louis, the cities fall along a smooth curve: Those that had high unemployment in 1965 still suffered it in 1969 and those with low rates in earlier years continued to experience them. Before embracing the structural hypothesis, however, I think it is appropriate to consider alternative

8. This is the only set of estimates of unemployment by city available annually for years before 1968. They are prepared from data on claims for unemployment insurance, payrolls, and various other sources. The Bureau of Labor Statistics has recently published estimates of unemployment rates by city from the household survey averaged over 1969. See Paul O. Flaim and Paul M. Schwab, "Geographic Aspects of Unemployment in 1969," Employment and Earnings, Vol. 16 (April 1970), pp. 5-6, 16-22. 
Figure 1. Relation between Unemployment Rates in 1965 and 1969, in Twelve Cities

Rate in 1969 (percent) ${ }^{\mathrm{a}}$

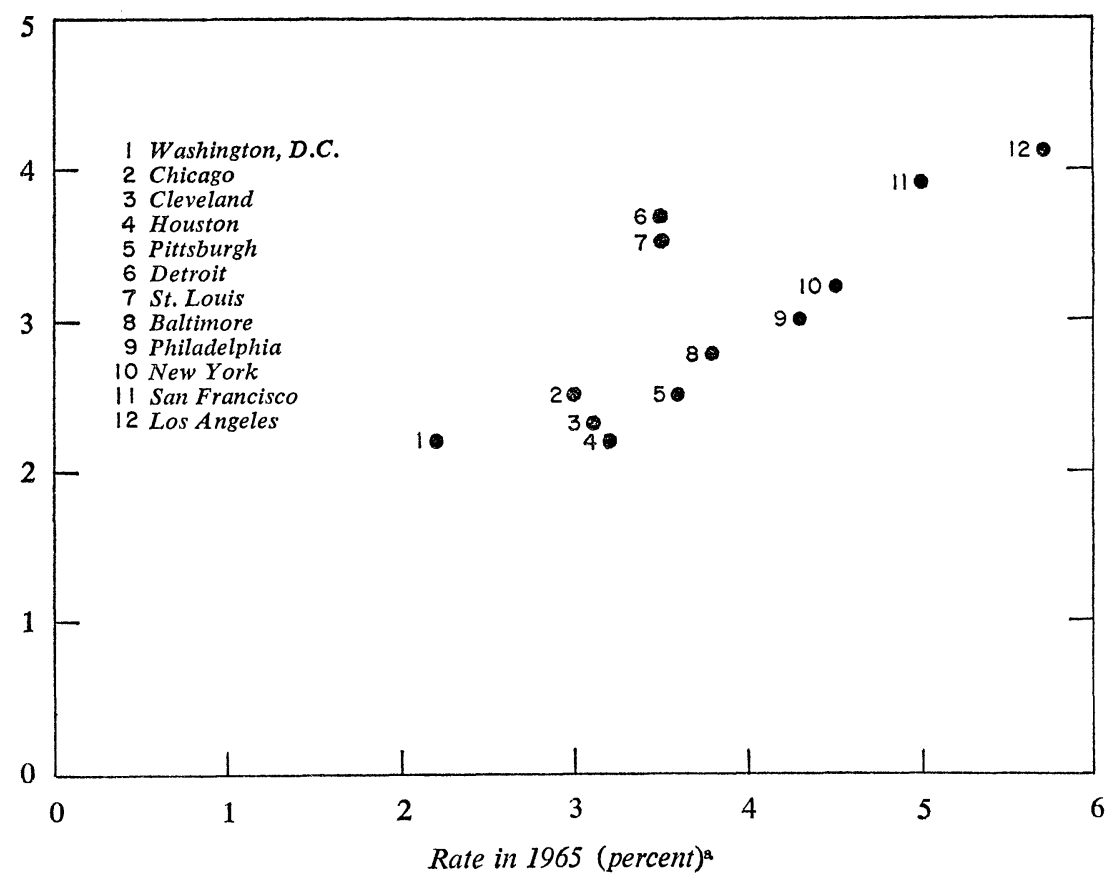

Source: Table 1.

a. Annual average of total unemployment as percent of total work force.

explanations of the persistent differentials in the unemployment rates of these cities.

In the first place, the unemployment rate for each city represents an average over the rates of disparate groups in the labor force. For example, teenagers invariably have high rates of unemployment, so if a city has an unusually large fraction of teenagers, its unemployment rate will be high relative to those of other cities even though neither its rate for adults nor its rate for teenagers is high. An adjustment for the varying composition of the labor forces of the twelve cities appears necessary before any meaningful conclusion can be drawn about the persistence of differentials in unemployment rates. 
It is not possible to adjust the data on unemployment by city from the Manpower Administration or from the household survey for compositional differences other than race. However, in a study of data on individuals that is reported briefly in the appendix, ${ }^{9}$ the statistical method of regression is used to estimate the pure differentials between the unemployment rates (or more precisely, weeks of unemployment per year) in the twelve cities, for the four sex-race groups, simultaneously estimating the pure effects of age, marital status, family size, income, and wages. The wage effects are particularly important, and I will return to them in a later section. For the moment, the fact that the estimates of the pure geographical effects take account of wage differences means that cities with unusually large proportions of well-paid workers (who generally have very low rates of unemployment) are put on an equal footing with those having more typical labor forces.

Important as this kind of adjustment is in principle, it turns out to make remarkably little difference in this case. Table 2 presents the pure geographical effects estimated from the regression. Simple averages calculated from the same data are remarkably similar, indicating that the adjustment for composition has little practical effect on the estimates of the differentials among the rates of unemployment in the twelve cities. The adjustments for composition that would be appropriate for the annual data from the Manpower Administration discussed above would be very much the same, so it seems safe to conclude that the annual data would be little changed by this kind of adjustment. The high correlation between the differentials by city for white males estimated from the Survey of Economic Opportunity (SEO) data and the data for 1966 from the Manpower Administration makes this conclusion even more tenable.

This seems to rule out the simple explanation that the persistent differentials in unemployment by city are the result of corresponding differences in the composition of the labor forces of the cities. The structural hypothesis seems to be the winner. Must optimists now abandon their view that, left to themselves, the equilibrating forces of labor mobility and changes in relative wages will gradually eliminate differentials in unemployment rates? Perhaps so. I offer here a distinctly tentative hypothesis

9. Data for this study were obtained from the Survey of Economic Opportunity, conducted by the U.S. Bureau of the Census in the spring of 1967. The annual data refer to 1966. 
Table 2. Estimates of Weeks of Unemployment in Twelve Cities, by Sex and Race, 1966

\begin{tabular}{lccccc}
\hline \multirow{2}{*}{ City } & \multicolumn{2}{c}{ Men } & & \multicolumn{2}{c}{ Women } \\
\cline { 2 - 3 } \cline { 5 - 6 } & White & Black & & White & Black \\
\hline Baltimore & 1.7 & 3.1 & & 0.7 & 0.2 \\
Chicago & 1.3 & 2.3 & & 1.1 & 0.6 \\
Cleveland & 1.6 & 3.2 & & 1.0 & 2.5 \\
Detroit & 2.8 & 5.5 & & 1.1 & 2.3 \\
Houston & 2.2 & 0.0 & & 0.8 & 0.6 \\
Los Angeles & 3.3 & 6.4 & & 1.5 & 2.2 \\
New York & 3.0 & 2.7 & & 1.3 & 1.0 \\
Philadelphia & 1.9 & 2.9 & & 1.0 & 1.5 \\
Pittsburgh & 2.8 & 4.5 & & 1.5 & 2.7 \\
St. Louis & 2.6 & 2.2 & & 1.0 & 4.2 \\
San Francisco & 3.6 & 8.0 & & 1.7 & 2.3 \\
Washington, D.C. & 2.0 & 2.2 & & 0.7 & 0.7
\end{tabular}

Source: Derived from regression estimates shown in Table A-1. The estimates are for individuals with specified characteristics. See the appendix for details.

that might explain the apparent weakness of the equilibrating forces in terms that should not be offensive to economists who have a basic faith in the efficacy of the price system.

In the data from the SEO, there is a positive association between average weeks of unemployment for men and average wages among the twelve cities. ${ }^{10}$ High-wage cities, notably San Francisco and Los Angeles, have high rates of unemployment, and low-wage cities tend to have low rates of unemployment. The data are presented in Figure 2 for men and women. If there is a general tendency for cities with high wages to have high unemployment rates, then there is no longer a presumption that geographical mobility of labor will act to reduce unemployment. The attraction of high wages may cancel or even outweigh the discouraging effect of unemployment. ${ }^{11}$ A rational worker might decide to move from Cleveland to Los

10. The wage rates used here are also adjusted for variations in the composition of the labor force by city. They are presented in Robert E. Hall, "Wages, Income, and Hours of Work in the U.S. Labor Force," Working Paper 62 (Massachusetts Institute of Technology, Department of Economics, August 1970; processed).

11. Unemployment does not necessarily exert its discouraging effect directly. Rather, high unemployment may be a sign of low rates of job vacancies. 
Angeles even though it is much harder to find a job in California, precisely because wages are significantly higher there. In this situation, geographical mobility of labor may not function at all as an equilibrating force. If the decisions of most families about their locations are influenced mainly by consideration of the husband's employment, then the relationship between unemployment and wages should be stronger for men than for women.

What about the other main equilibrating force, changes in relative wages? Deeply embedded in modern economic thought is the idea that excess supply of labor in a market should drive down the wage, at least relative to the average wage in all markets. It is, for example, the explanation of the Phillips curve. The basic mechanism that economists usually have in mind is that in a market where unemployment is high, employers find it possible to hire at slightly lower wages, or at least they need not keep up with wage increases in other markets in order to fill their jobs. In this view, the pool of unemployment consists of workers who are increasingly desperate for work, and who will take somewhat lower wages than they had originally expected. I have suggested above, however, that those unemployed in a city with high wages may have a rather different attitude: They may be in the market precisely because they are willing to pay the price of a spell of unemployment in order to locate a high-paying job. If so, there is no reason to expect this kind of unemployment to exert a downward pressure on wages. The employer who offered a job at a slightly reduced wage to an unemployed worker would simply be refused.

One final question needs to be answered to complete this explanation. Why do employers hire in cities with high wages rather than relocating in low-wage areas? In the long run, one might expect the mobility of employers to bring about equalization of wages, even if the other forces were not acting to do so. ${ }^{12}$ However, the existence of unemployment in his labor market is a distinct advantage to the employer. It acts to stabilize his work force, reducing his hiring costs and permitting him to capture the benefits of training that his workers acquire on the job. The existence of a high level of unemployment imposes a substantial price on workers who change jobs,

12. Of course, other factors as well determine the geographical pattern of wages. In an ideal set of labor markets, one would expect uniformly low unemployment rates and differences in wages that reflected only these other determinants. Climate is the obvious example of such an influence. By equalization, then, I really mean equalization after taking these other determinants into account. 
Figure 2. Relation between Average Wages and Weeks of Unemployment in Twelve Cities, by Race and Sex, 1966

Weeks of unemployment
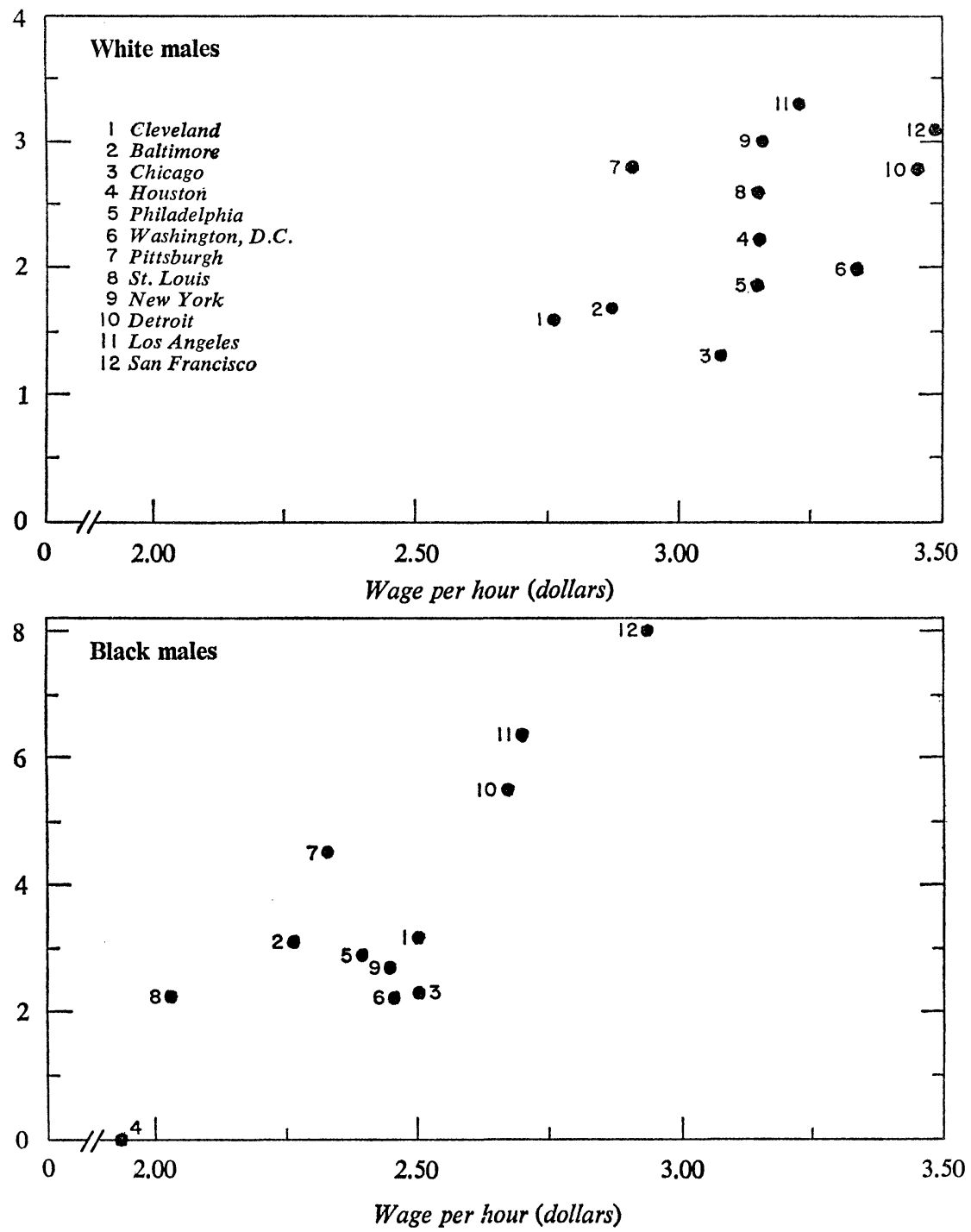


\section{Figure 2. (continued)}

Weeks of unemployment
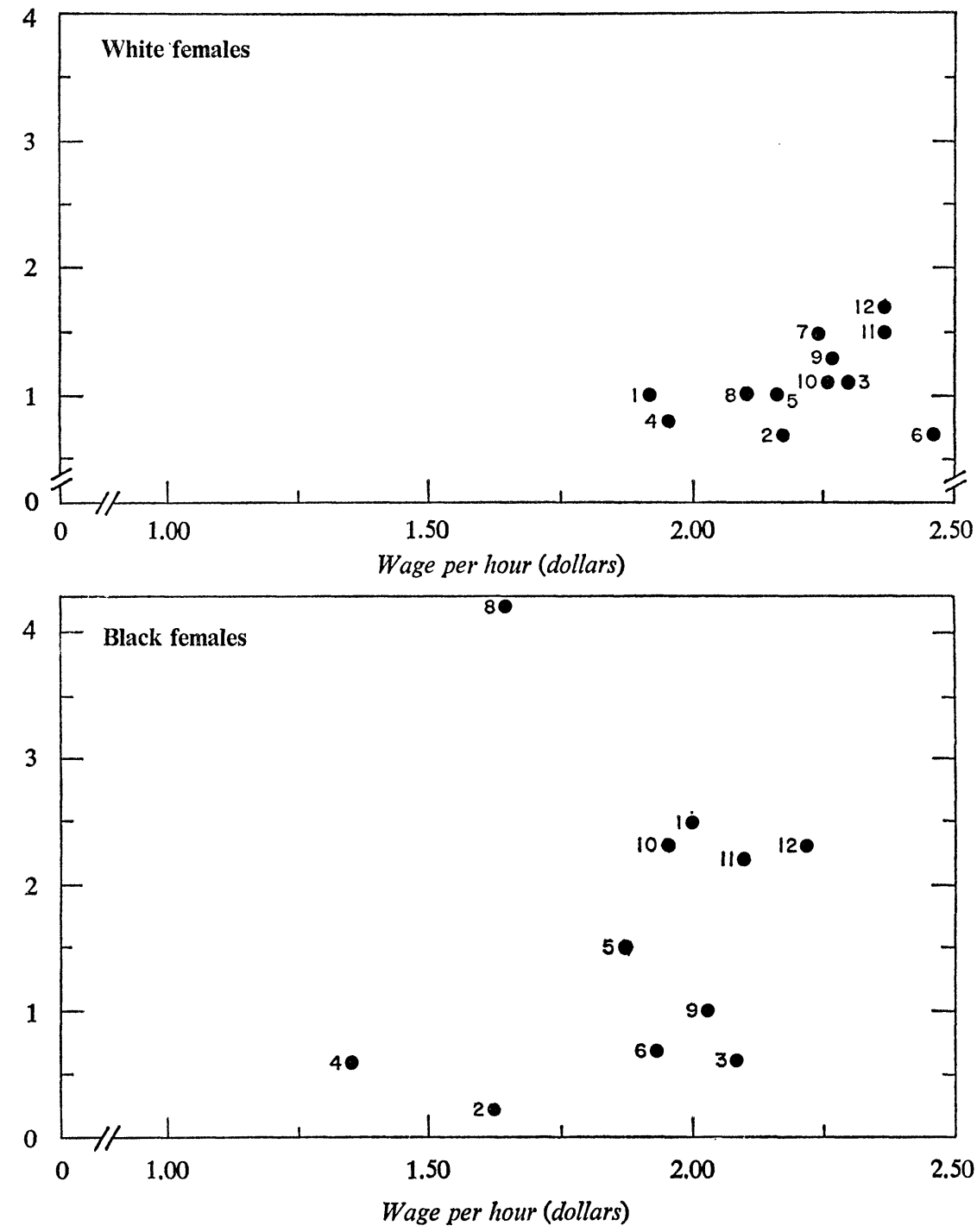

Source: Wages-Robert E. Hall, "Wages, Income, and Hours of Work in the U.S. Labor Force," Working Paper 62 (Massachusetts Institute of Technology, Department of Economics, August 1970; processed), p. 25; weeks of unemployment-Table 2 . 
and materially reduces the frequency with which workers do so voluntarily. The prospective employer, deciding where to locate, can buy stability in his work force by locating in a high-wage, high-unemployment city.

Taken together, these arguments suggest that there can be an indeterminacy of the equilibrium in the labor market of a city. There may be a whole set of unemployment-wage combinations each of which represents equilibrium in the sense that it can be maintained indefinitely. None of the combinations is really satisfactory, and it would be unfortunate to suppose that the goal of manpower policy should be to try to move to a position of low unemployment and accept the consequent low wage. If some other means, less costly than unemployment, could be found to reduce turnover, then the equilibrium could be at high wages and low unemployment.

\section{Is There a Substantial Amount of Chronic Unemployment at Full Employment?}

Popular accounts of unemployment often seem to suggest that full employment leaves behind a residual group of chronically unemployed workers who are unable to find work over long periods of time. I interpret the notion of chronic unemployment to refer to individuals who are literally unable to find a job after looking for six months or more. This is a very stringent definition (some might say it is a caricature of the usual idea of chronic unemployment); I use it because there is still a very large difference between having difficulty finding a job (spending up to six months searching), and not being able to find a job at all. Nothing in my definition is intended to suggest that there is not a great deal of hardship in four or five months of joblessness. I wish to suggest only that it is misleading to label a spell of unemployment of this length as chronic unemployment. I think it important to distinguish between truly chronic unemployment, in which the same individuals remain unemployed month after month, and unemployment involving continual, even if relatively slow, turnover among the unemployed.

The first place to evaluate the importance of chronic unemployment is in the data on the duration of unemployment. ${ }^{13}$ Table 3 presents these data

13. These data are particularly sensitive to the kinds of errors discussed in pp. 373-75. In particular, unemployed individuals seem to have a tendency to date their spells of 
Table 3. Percentage Distribution of Unemployment in Sex and Age Groups, by Duration, April 1969

\begin{tabular}{lcccc}
\hline & \multicolumn{4}{c}{ Weeks of unemployment } \\
\cline { 2 - 5 } \multicolumn{1}{c}{ Sex and age } & $0-4$ & $5-14$ & $15-26$ & 27 or more \\
\hline Both sexes, 16-19 years & 60.1 & 25.6 & 7.3 & 7.0 \\
Male, 20 years and over & 47.9 & 26.2 & 18.4 & 7.4 \\
Female, 20 years and over & 55.1 & 25.6 & 14.5 & 4.9 \\
\hline
\end{tabular}

Source: Employment and Earnings, Vol. 15 (May 1969), Table A-13, p. 39.

for April 1969, a month of high employment. About half of those unemployed in that month had become so within the previous four weeks. Only a very small fraction had been unemployed for six months or more: in the case of adult men, 7.4 percent of the total, or about 70,000 individuals. If chronic unemployment is a major social problem when the economy is at full employment, that fact is not revealed in the data on unemployment from the household survey. Those data show that individuals leave the status of unemployment relatively rapidly; very few of them are reported as unemployed for long periods.

The definition of unemployment used in the survey practically guarantees that little chronic unemployment will be reported. If an individual is unable to find work after searching for several months, he may well not take the trouble to engage in specific job-seeking activities in the four weeks preceding the survey. In an earlier section I discussed the new data on individuals not in the labor force who nonetheless desire a job or would normally be in the labor force. It is now useful to take a second look at this group, which is not very large compared with total unemployment, but is certainly large enough so that if it comprised mainly those permanently out of work, it would indicate that chronic unemployment was a major problem. In February 1967, the Bureau of the Census carried out a follow-up survey of men aged 20 through 64 who were reported as not in the labor force in the regular monthly survey one week earlier. ${ }^{14}$ Most of them were sick or dis-

unemployment from the month when they entered the survey. Since each household spends only four consecutive months in the survey, this bias may cause an understatement of very long-term unemployment.

14. Vera C. Perrella and Edward J. O'Boyle, "Work Plans of Men Not in the Labor Force," Monthly Labor Review, Vol. 91 (August 1968), pp. 8-14. 
abled (59.0 percent) or retired (10.7 percent). Almost 700,000 men, however, were out of the labor force for unusual reasons-that is, for reasons other than poor health or retirement. Might not some fraction of these be chronically unemployed? The survey seems to rule this out almost completely. Astonishingly enough, just under half of those who had been out of the labor force the previous week were back in it by the time the followup survey was made. Table 4 gives the complete breakdown by age groups

Table 4. Status of Men One Week after Being Recorded as Not in the Labor Force for Unusual Reasons, February 1967

Thousands

\begin{tabular}{lccc}
\hline \multirow{2}{*}{ Status } & \multicolumn{3}{c}{ Age group } \\
\cline { 2 - 4 } & $\begin{array}{r}20-34 \\
\text { years }\end{array}$ & $\begin{array}{c}35-59 \\
\text { years }\end{array}$ & $\begin{array}{c}\text { 60-64 } \\
\text { years }\end{array}$ \\
\hline Now in labor force & 86 & 191 & 64 \\
Expect to be in labor force within four weeks & 24 & 85 & 20 \\
Want a job but not looking & 18 & 62 & 48 \\
Do not want a job & $\frac{24}{152}$ & $\underline{36}$ & $\frac{41}{173}$ \\
$\quad$ Total & 154 & $\frac{173}{2}$
\end{tabular}

Source: Vera C. Perrella and Edward J. O'Boyle, "Work Plans of Men Not in the Labor Force," Monthly Labor Review, Vol. 91 (August 1968), pp. 8-14. Derived by excluding the categories "sick or disabled" and "retired" from their Table 2, p. 10.

and status at the time of the follow-up survey. ${ }^{15}$ In the two younger age groups almost three-quarters of those who had been out of the labor force were either back in it or planned to be within four weeks. Men 60 and above account for a substantially disproportionate share of those who might be chronically out of the labor force while still desiring to work. The results of the survey show that ill health is the main cause of temporary withdrawal from the labor force. For example, about half of those who planned to be back in the labor force within four weeks reported that illness, accident, or other disability was responsible for their withdrawal. Only 22 percent gave reasons related to unavailability of work, and most of them were construction workers experiencing a seasonal lull in February. The others gave various reasons, such as recent discharge from military service and bad weather. Similarly, health problems were cited by more

15. These data are even more prone to error than those from the regular survey, since they are subject to an unknown bias caused by the unusual interviewing schedule. 
than half of those who wanted jobs but were not looking. ${ }^{16}$ No similar data seem to be available for those who were back in the labor force at the time of the interview. Nothing in the survey supports the hypothesis that unavailability of work is an important cause of withdrawal from the labor force. The overwhelming impression from these data is that the rate of turnover among those who are out of the labor force for unusual reasons is, if anything, greater than the rate of turnover among the unemployed. In neither group is there evidence of a substantial number of individuals who are chronically out of work.

The very large flow into the labor force of individuals who were out of the labor force for unusual reasons suggests that the latter status represents a temporary way station occupied partly by people who are about to start looking for work. If so, the distinction between those who are unemployed and those who are temporarily out of the labor force is rather arbitrary. A more comprehensive definition of the labor force and of unemployment would include those individuals who are about to start looking for work. The data necessary to distinguish between them and those who are temporarily unable to work are not available, however.

The evidence just presented does not show conclusively that there are few individuals who are permanently unable to find work. The evidence is consistent with the presence of large numbers of individuals who oscillate between unemployment and withdrawing from the labor force without ever finding work. In fact, those in the special survey who were reentering the labor force had suffered in the previous year from substantially more unemployment than did typical members of the labor force. However, a very large fraction - seven out of eight-of those returning to the labor force who were in it in the previous year had worked at some time during that year. ${ }^{17}$ Most of those who did not work at all probably looked for work only a small part of the year.

Taken together, the evidence on the duration of unemployment and on individuals who are not in the labor force suggests rather strongly that chronic inability to find a job is not a problem faced by a significant number of people when the economy is at full employment. The real problem is that many workers have frequent short spells of unemployment. This is the topic of the next section.

16. Vera C. Perrella and Edward J. O'Boyle, "Work Plans of Men Not in the Labor Force," Monthly Labor Review, Vol. 91 (September 1968), pp. 35-36.

17. Ibid., p. 35. 


\section{Frictional Unemployment and Turnover in the Labor Force}

Economists have generally recognized that a certain amount of unemployment will always arise in the normal operation of a labor market. Especially when unemployment is defined in terms of activity in looking for a job, a certain fraction of the nonworking population will be searching for work whenever the household survey is conducted, and will be measured as unemployed. At full employment, in fact, a good fraction of those unemployed are at natural transition points in their careers where it is normal to be looking for jobs; those who have just finished school or have just been discharged from the military are the obvious examples. In April 1969, individuals with no previous work experience constituted over 11 percent of total unemployment and reentrants to the labor force constituted another 30 percent. Experienced workers may seek new jobs, either because they have exhausted the possibilities for training and advancement in their old jobs, or because technical progress or shifts in the composition of demand have eliminated their previous jobs. Unemployed individuals who are changing jobs may have been laid off, or they may have quit in the belief that more favorable opportunities exist elsewhere. These two sources accounted for 43 and 16 percent, respectively, of total unemployment in April 1969. Unemployment that arises from any of these sources need not be a subject of social concern if the unemployed find jobs reasonably rapidly; in fact, labor markets could not function efficiently if workers did not spend some fraction of their time searching for the best possible jobs.

This observation has led some economists to adopt normal turnover as a unitary explanation of unemployment. The resulting doctrine is rather loosely called the Search Theory of Unemployment. ${ }^{18}$ It emphasizes that it is rational for an unemployed worker not to take the first job available, but to wait long enough to get a particularly good job. This incentive to remain unemployed operates even when the demand for labor is exceedingly strong, so there is a level of frictional unemployment that is the irreducible minimum that can be achieved by expansionary fiscal and monetary policy.

In the search theory, unemployment is a transitory experience, generally associated with voluntary or involuntary changes in jobs. The appropriate

18. Many interesting papers on the search theory and related topics appear in Edmund S. Phelps and others, Microeconomic Foundations of Employment and Inflation Theory (Norton, 1970). 
policy for reducing unemployment, then, is to eliminate some of the friction in the labor market. The policy conclusions of the search theory are typified by Charles C. Holt's ingenious suggestion that the offices of the U.S. Employment Service should be kept open at night so that workers can search for new jobs before quitting their old ones. ${ }^{19}$ To practical economists, something is missing here. In the course of providing a firm logical foundation for the traditional notion of frictional unemployment, the search theory seems to claim that all unemployment is frictional, that every person who reports himself as out of work is spending a few weeks between jobs in the normal advancement of his career. In his discussion of Holt's and Phelps' work, Otto Eckstein puts this point forcefully: “. . . the central employment problem of our society today is the disparity of employment opportunities among blacks and whites, among skilled and unskilled, among young and experienced. ... We are in danger of devising a labor market theory which is as remote from the central employment problem of our times as the classical theory was in the 1930's." 20

In the previous section I tried to show that chronic unemployment is not the central employment problem of our time, either. Whatever the merit of Eckstein's criticism, it does not appear that the search theorists are wrong in looking at the problem of unemployment from the point of view of turnover in the labor force. The central problem seems to be that some groups in the labor force have rates of unemployment that are far in excess of the rates that would accord with the hypothesis that the unemployed are making a normal transition from one job to another. Some groups exhibit what seems to be pathological instability in holding jobs. Changing from one low-paying, unpleasant job to another, often several times a year, is the typical pattern of some workers. The resulting unemployment can hardly be said to be the outcome of a normal process of career advancement. The true problem of hard-core unemployment is that certain members of the labor force account for a disproportionate share of unemployment because they drift from one unsatisfactory job to another, spending the time between jobs either unemployed or out of the labor force. The most compact evidence supporting the existence of such

19. "Improving the Labor Market Trade-off between Inflation and Unemployment," in American Economic Association, Papers and Proceedings of the Eighty-first Annual Meeting, 1968 (American Economic Review, Vol. 59, May 1969), p. 142.

20. "Discussion," in American Economic Association, Papers and Proceedings (May 1969), p. 163. 
a group is provided by the data on the number of spells of unemployment experienced by the labor force. Among those who were unemployed at some time in 1968, 69 percent had only one spell of unemployment, 15 percent had two spells, and 16 percent had three or more. ${ }^{21}$ The overall unemployment rate in 1968 was 3.6 percent, and the average unemployed person required about one month to find a new job. The implied average duration between spells of unemployment was about twenty-seven months. In order to have two, much less three, spells of unemployment in the same twelve months, an individual could hardly be making normal changes in jobs. Yet almost a third of those unemployed at all in 1968-more than 3 million individuals-had two or more spells. The existence of this group is surely a matter of social concern.

In order to identify groups in the labor force who suffer from excess unemployment at full employment, it is necessary to make a crude guess about the amount of unemployment that arises from normal turnover. I have done this by making a set of assumptions about the time required to find a job and the frequency with which individuals of various ages change jobs. ${ }^{22}$ From this I have calculated the implied rates of unemployment by age groups, as shown in Table 5. The assumptions are as follows: (1) An individual looking for his first job requires, on the average, two months to find it, but he requires only one month to find subsequent jobs; (2) teenagers change jobs every year, young adults every two years, and adults (age 25 and over) every four years; (3) the pattern of entry into the labor force yields the distribution between inexperienced and experienced members shown in columns 1 and 3 of Table 5. The resulting hypothetical normal rates of unemployment appear in column 6 of the table. With the distribution of the labor force among age groups prevailing in 1969, the overall normal unemployment rate would be 3.3 percent, not a great deal below the actual rate of 3.5 percent. The last four columns show why this is so. White males, the largest of the four sex-race groups, actually had unemployment rates below the hypothetical normal rates in every age group in April 1969. This probably demonstrates that the assumptions used in making the calculations are a little pessimistic, although it should be kept in

21. Vera C. Perrella, "Work Experience of the Population," Monthly Labor Review, Vol. 93 (February 1970), Table 2, p. 57.

22. These are purely assumptions and are not drawn from any data. Actual data would, of course, include the effects of the abnormal unemployment I am trying to distinguish. 


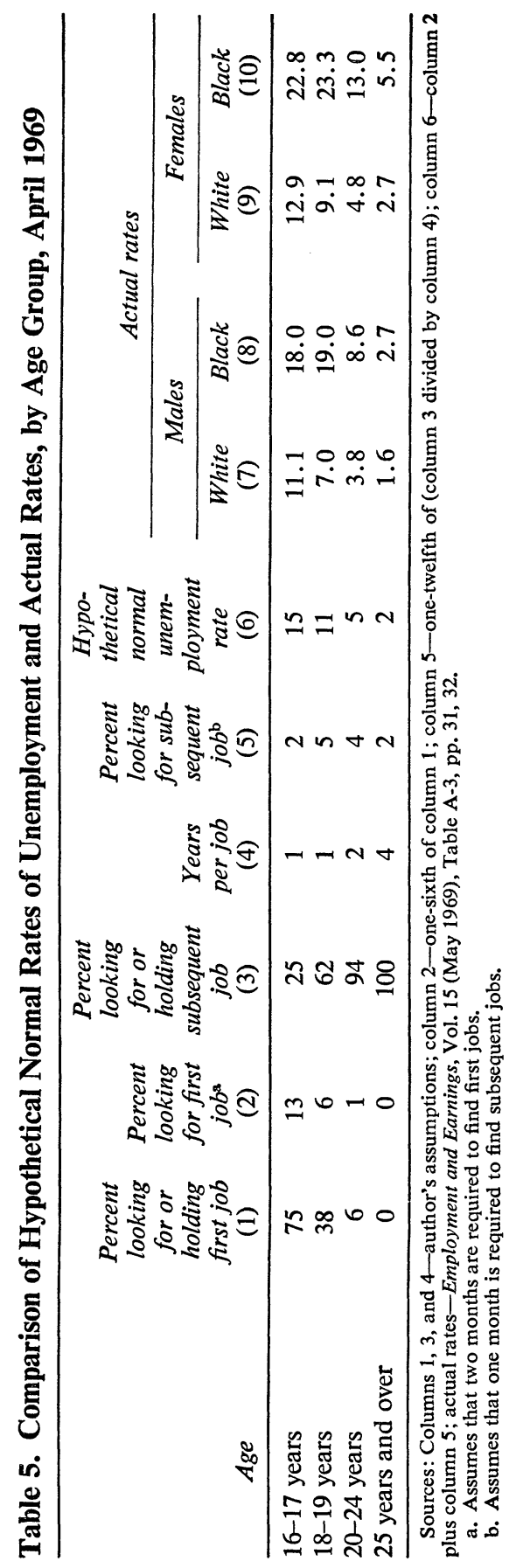


mind that April 1969 was a month of over-full employment and not one of equilibrium as I defined it at the beginning of the paper. It is important to note that if my assumptions are anywhere near the truth, the differentials between the unemployment rates of teenagers and adults among white males are a normal consequence of the process of looking for jobs and are not an indication of a special problem for teenagers. For black males, the situation is altogether different. Rates of unemployment are about 35 percent greater among adult black males than the hypothetical values, and are even higher for 18- and 19-year-olds. Nothing in the theory of turnover or frictional unemployment seems capable of explaining this extraordinary discrepancy. Blacks are poorly educated and poorly trained in comparison to their white counterparts, and they suffer from discrimination as well, but those facts do not adequately explain why they should take longer to find a job or why they should change jobs more often. In the framework of the search theory, a satisfactory explanation would involve demonstrating that it is in the interest of disadvantaged workers to search for jobs more often and for longer periods. I shall have a little more to say about this matter in a later section, but it remains an urgent unsolved problem of modern economic research.

White females have unemployment rates somewhat below the hypothetical levels in all but the highest age group. These and other data suggest that the main problems experienced by white females in the labor force arise not in their early years in the labor force, but after age 25 . For example, as I shall show in the next section, wages paid to white females are almost as high as those paid to white males up to age 25 , but after that age wages paid to men rise steadily while those paid to women remain at essentially the level of age 25 .

Finally, black females suffer the largest discrepancy of all between actual and hypothetical unemployment rates. In fact, they suffer more than doubly for being black and for being women: In every category their unemployment rate exceeds the rate of white females by more than the difference between black and white males.

I conclude, then, that only among white males is normal turnover a satisfactory unitary explanation of the observed levels of unemployment by age groups. Signs of pathological excess unemployment appear in the data for women and blacks. Even for white males, unemployment is distributed unevenly between high- and low-paid workers, as I will show in the next section. 


\section{Workers Who Are Unemployed Frequently}

Earlier in this paper I have argued that the problem of hard-core unemployment at full employment is not so much that there are individuals who are permanently out of work as that there are many workers who move frequently from job to job without advancing their careers. Further study of the problem ought logically to be carried out with data on the experience over time of a representative sample of members of the labor force. The existence of groups with unstable work histories could be confirmed and the nature of the problem examined more deeply with such data. The only data available, however, give information about the status of individuals only for a single year. This makes it necessary to infer conclusions about the experience of an individual over time from the status of similar individuals of different ages at the same point in time.

To an economist, the natural way to measure the progress of an individual worker is by his wage. As he accumulates experience and specialized training on the job, his hourly wage should rise year by year. At a point in time, then, the age profile of wages should rise smoothly with age, provided that an appropriate adjustment is made for the fact that older workers tend to have less formal education and may tend to live in areas with lower wages. From the data in the Survey of Economic Opportunity, I have made estimates of the pure age profile of hourly wages, incorporating adjustments for years of education, location, union membership, health, and country of birth. The results are presented in Figure 3. They suggest that the whole notion of a career with steady advancement is relevant only for white males, whose wages rise through ages 45 to 54 . Black males, and women of both races, make progress only through ages 20 to 24 . From ages 25 to 34 onward, their wage profiles are practically flat.

From data on the status of a sample of individuals at a single point in time, something can be inferred about the proportion of time that individuals with various characteristics spend looking for work, although there is no way to tell if a high proportion is the result of many short spells or a few long ones. Within each of the four sex-race groups in the SEO sample, unemployment is very unevenly distributed. In general, workers with few skills are much more likely to be unemployed than others. Once again, to an economist, the natural overall measure of an individual's level of skill is the wage he earns, or would earn if he were working. To adjust for the 
Figure 3. Age Profile of Wages, by Sex and Race, 1966

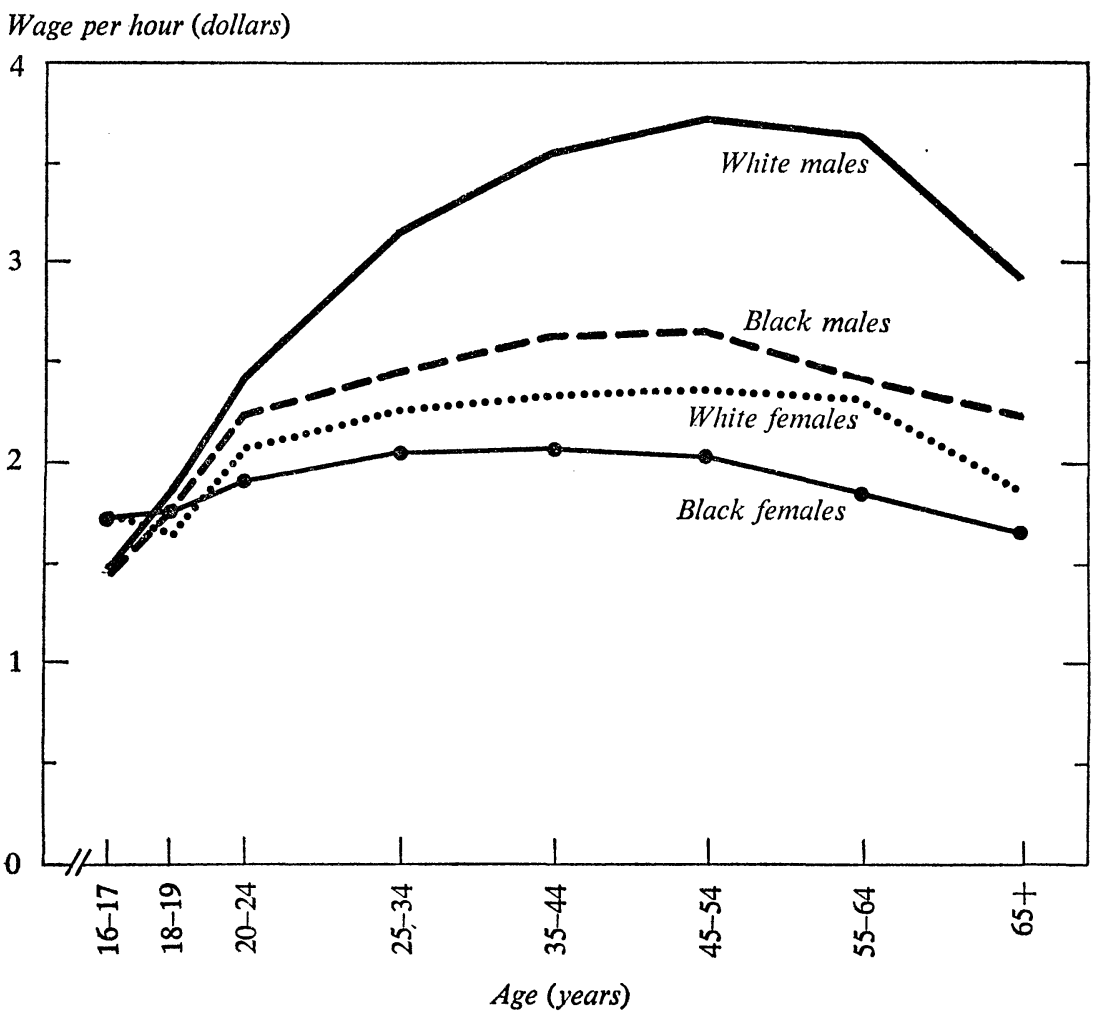

Source: Hall, "Wages, Income, and Hours of Work," Table 2-2, p. 23.

tendency for well-paid workers to live in cities where unemployment rates are high, and for other related effects, it is necessary again to use estimates of the pure effects obtained by regression. These are presented in Table 6 and incorporate adjustments for age, marital status, number of children, income, and location.

White males in the lower wage groups experience unemployment of moderate length; the length declines to the relatively low rate of 1.4 weeks per year in the highest wage group. Black males, in contrast, have much longer periods than whites in the lower wage groups, and shorter ones in the higher groups. ${ }^{23} \mathrm{I}$ offer the following tentative explanation for this

23. The negative value for the highest wage group for black males serves as a reminder that these results are subject to a certain amount of statistical variation. 
Table 6. Estimates of Weeks of Unemployment, by Race, Sex, and Wage Groups, 1966

\begin{tabular}{cccccc}
\hline \multirow{2}{*}{$\begin{array}{c}\text { Hourly wage } \\
\text { in dollars }\end{array}$} & \multicolumn{2}{c}{ Men } & & \multicolumn{2}{c}{ Women } \\
\cline { 2 - 3 } \cline { 5 - 6 } \cline { 5 - 6 } & White & Black & & White & Black \\
\hline $0-1.50$ & 4.3 & 9.4 & & 1.3 & 1.0 \\
$1.50-1.75$ & 2.8 & 8.3 & & 1.1 & 1.3 \\
$1.75-2.00$ & 2.8 & 4.9 & & 1.0 & 1.6 \\
$2.00-2.50$ & 3.0 & 2.7 & & 0.8 & 1.2 \\
$2.50-3.00$ & 2.0 & 0.0 & & 0.9 & 0.3 \\
3.00 or more & 1.4 & -1.0 & & 0.0 & 0.6 \\
\hline
\end{tabular}

Source: Derived from regression estimates shown in Table A-1 for married individuals, aged 20 through 59, with no children, living in the New York Standard Metropolitan Statistical Area, and with family incomes between $\$ 3,750$ and $\$ 4,500$ per adult per year.

difference: Whites are willing to work steadily at low-paying jobs because they are aware that they can start up a job ladder by establishing a stable employment record. Blacks, on the other hand, do not seem to have this opportunity, and therefore are likely to leave a low-paying job within a few months or a year. Thus trainees in banks and workers in service stations receive about the same hourly wages, but the trainees have an incentive to work hard and steadily that is absent for the service station men. A few blacks accomplish what is routine for whites, however, so in the higher wage groups there is much more selection of the most stable workers among blacks than among whites.

Racial differences among women are not as pronounced, perhaps because women of both races are generally excluded from the job ladder. Note that although women have higher unemployment rates than men, as reported in the household survey, they have fewer weeks of unemployment per year. The unemployment rate in a group is, roughly speaking, the ratio of weeks of unemployment to weeks in the labor force, and women tend to spend substantially fewer weeks in the labor force than men.

Economists are occasionally tempted to speculate about another source of unemployment: For many people only low-paying, unpleasant jobs are available, either because of lack of skills or because of discriminatory exclusion. If they have income from sources other than their own work, they might work only part time, or more likely, part of the year, and enjoy leisure (which is cheap for them) the rest of the time. Moving in and out of the labor force would cause them to be recorded as unemployed frequently. Further, a person who feels guilty about not working might report himself 
as unemployed even though he was not actually interested in taking the kind of job he could get. Both of these kinds of unemployment are voluntary in that they are different from the unemployment suffered by a person who is simply unable to find a job despite serious effort. One implication of this argument seems to be that unemployment ought to be positively associated with income from sources other than an individual's own work. In the regressions presented in the appendix and discussed above, I have controlled for income as well as wages, using a comprehensive measure of income that includes the nonwage income of the family and estimates of the wage income of other members of the family. It also includes the value of the individual's own time, but this does not affect the interpretation, since his wage is included separately. Income does not include the individual's actual wage income, of course, since that depends on his amount of unemployment. The income effects in all four regressions are quite small, and generally have signs that are the opposite of those predicted by the theory just mentioned. If anything, individuals in a given wage group tend to have more unemployment if their families are poor. There is no evidence whatever in favor of the hypothesis that unemployment is voluntary in the sense defined above.

Earlier sections of the paper have suggested how these data on individuals at a single point in time ought to be interpreted. They show who is likely to become unemployed for a spell one or more times during a year, not who is likely to remain permanently out of a job. Blacks and women seem to be excluded from work that offers an incentive to stay with a job permanently, and spend much larger fractions of their time in the labor force looking for new jobs than do white males. Within each group, the lower-paid members spend many more weeks looking for work than do the higher-paid ones. Finally, even with the wage level held constant, higher income seems to reduce weeks of unemployment. 


\section{APPENDIX}

\section{A Study of Weeks of Unemployment in 1966}

THE DATA OF THIS STUDY are somewhat different from those in the monthly household survey, and probably suffer from all of the difficulties of the household survey and from some of their own as well. They are taken from the Survey of Economic Opportunity (SEO) for 1967, a body of data collected by the U.S. Bureau of the Census using roughly the same methods that it employs in the monthly survey. The questions about unemployment referred not to the status of the adults in the family at the time of the survey (spring 1967), but rather to their experience throughout the previous year, 1966. The respondent was asked, "How many different weeks was looking for work or on layoff from a job?" The definition of looking for work is much less strict than that used in the household survey. As stated in the SEO codebook: "The interviewer was told to accept the answer of the respondent if he says a person was looking for work. If the respondent is in doubt about what the phrase 'looking for work' means, the interviewer was to use this explanation-a person is 'looking for work' if he is trying to get work or trying to establish a business or profession . . . 'Layoff' includes both temporary and indefinite layoff." 1 The data from the extended household survey suggest that the use of this relaxed definition does not tend to classify a great many people as unemployed who would otherwise be classified as not in the labor force. A more serious deficiency of this body of data arises from its retrospective nature. If the respondent has difficulty reporting the current status of the members of his or her household for the monthly survey, surely the difficulties are compounded many times in reporting on their status up to fifteen months earlier. To the extent that errors of perception and memory are random and uncorrelated with the determinants of unemployment, the results are not biased by the errors; they are only made less precise. But there is every reason to believe that the errors are systematic and the empirical results should always be

1. "1967 Survey of Economic Opportunity Codebook" (Office of Economic Opportunity, no date; processed), pp. 191-92. 
interpreted with this in mind. In particular, comparisons between men and women are rather dangerous.

The purpose of this study is to obtain averages of unemployment levels for various demographic and economic groups. Averages for groups in one classification (for example, various wage groups) need to be adjusted for variations in other determinants of unemployment. Simple tabulation of averages does not allow for this adjustment; for example, classification by wage groups alone would understate the magnitude of the pure wage effect because high-wage workers tend to live in high-wage cities, where unemployment is higher. Cross-tabulation by all classifications simultaneously is infeasible because of the large number of groups. I have therefore adopted the method of regression on dummy variables to estimate the pure averages within each classification. The adjustment for the association between wages and cities, for example, has the following character: All cities have the same pattern of unemployment by wage groups, but each city has its own overall level of unemployment. Equivalently, one can say that all wage groups have the same pattern of unemployment by city, but each wage group has its own overall level.

The definitions used in the various classifications are precisely the same as those in the author's study of hours of work, ${ }^{2}$ which the reader should consult for additional information. In brief, the characteristics are defined in the following way:

1. Race

a. White, including chicanos and Puerto Ricans.

b. Black. Other nonwhites, mainly Orientals, were excluded.

2. Sex
a. Male.
b. Female.

3. Position in family

a. Head or spouse of head, spouse present.

b. Head, spouse absent. Only women were included in this classification; a small number of male heads without wives were excluded.

c. Single individual.

d. Relative, living in a family but not the head. This includes sons,

2. Hall, "Wages, Income, and Hours of Work." 
daughters, parents (when not the heads), aunts, uncles, and so forth.

4. Age

a. 14 through 19. Since individuals who were in school all or part of the year were excluded, this group consists mainly of 18- and 19-year-olds.

b. 20 through 59 .

c. 60 and over.

5. Children in the family
a. None.
b. Preschool age only (6 or younger in March 1967).
c. School age only (7 through 13$)$.
d. Both.

6. Income. For each family, a comprehensive measure of income was calculated in the following way: (a) Nonlabor income was estimated as the sum of reported unearned income and the imputed income on the equity value of durable wealth; (b) the value of the time of each member of the family was calculated as the product of the number of hours available to be divided between work of all kinds and leisure (taken as 2,000 hours per year for most individuals) and his wage rate (imputed by the method described below); (c) the sum of these components was adjusted for the influence of the federal income tax. The resulting measure of income, called whole income, was classified in the following way:
a. $\$ 0$ to $\$ 3,000$ per adult per year.
b. $\$ 3,000$ to $\$ 3,750$.
c. $\$ 3,750$ to $\$ 4,500$.
d. $\$ 4,500$ to $\$ 5,500$.
e. $\$ 5,500$ or more.

7. Hourly wage. For each individual, whether working or not, a wage is imputed on the basis of his personal characteristics. The imputation is derived from a first-stage regression in which observed hourly earnings in the week before the survey is the left-hand variable. The imputed wage per hour was adjusted for the marginal income tax paid by the individual, and classified as follows:
a. $\$ 0.00$ to $\$ 1.50$.
b. $\$ 1.50$ to $\$ 1.75$. 

c. $\$ 1.75$ to $\$ 2.00$.
d. $\$ 2.00$ to $\$ 2.50$.
e. $\$ 2.50$ to $\$ 3.00$.
f. $\$ 3.00$ and above.

8. Location. Twelve large metropolitan areas are identified explicitly in the SEO. Each is labeled by the name of the largest city it contains, but the area includes the entire Standard Metropolitan Statistical Area (SMSA). The areas are:
a. Baltimore.
b. Chicago.
c. Cleveland.
d. Detroit.
e. Houston.
f. Los Angeles.
g. New York.
h. Philadelphia.
i. Pittsburgh.
j. St. Louis.
k. San Francisco.
1. Washington, D.C.

Separate regressions were computed for the four race-sex groups. The results are presented in Table A-1.

Table A-1. Determinants of Weeks of Unemployment in 1966, Regression Results

\begin{tabular}{lcccccc}
\hline \multirow{2}{*}{ Characteristic and value } & \multicolumn{2}{c}{ Men } & & \multicolumn{2}{c}{ Women } \\
\cline { 2 - 3 } \cline { 6 - 7 } Constant & White & Black & & White & Black \\
\cline { 6 - 7 } & 2.95 & 2.65 & & 1.25 & 0.96 \\
Position in family & $(0.41)$ & $(0.70)$ & & $(0.24)$ & $(0.57)$ \\
Head or spouse of head & & & & & \\
Single & - & & & & 0 & 0 \\
& 1.63 & 1.12 & & 0.61 & 1.17 \\
Relative & $(0.46)$ & $(0.70)$ & & $(0.22)$ & $(0.52)$ \\
& 0.02 & 2.71 & & 0.29 & 1.55 \\
Head without spouse & $(0.46)$ & $(0.68)$ & & $(0.24)$ & $(0.48)$ \\
& - & - & & 0.08 & 0.32 \\
& - & - & & $(0.30)$ & $(0.51)$
\end{tabular}


Table A-1 (continued)

\begin{tabular}{|c|c|c|c|c|}
\hline \multirow[b]{2}{*}{ Characteristic and value } & \multicolumn{2}{|c|}{ Men } & \multicolumn{2}{|c|}{ Women } \\
\hline & White & Black & White & Black \\
\hline \multicolumn{5}{|l|}{ Age } \\
\hline $14-19$ years & $\begin{array}{c}1.30 \\
(0.83)\end{array}$ & $\begin{array}{c}-4.65 \\
(1.10)\end{array}$ & $\begin{array}{c}0.55 \\
(0.42)\end{array}$ & $\begin{array}{c}1.85 \\
(0.68)\end{array}$ \\
\hline $20-59$ years & $\underline{0}$ & $\underline{0}$ & $\underline{0}$ & 0 \\
\hline 60 years and over & $\begin{array}{c}-0.94 \\
(0.37)\end{array}$ & $\begin{array}{c}-4.29 \\
(0.71)\end{array}$ & $\begin{array}{r}-1.09 \\
(0.22)\end{array}$ & $\begin{array}{c}-1.77 \\
(0.51)\end{array}$ \\
\hline
\end{tabular}

Children

None

$\begin{array}{cccc}0 & 0 & 0 & 0 \\ -0.16 & -0.35 & -0.57 & - \\ (0.35) & (0.60) & (0.21) & (0.48) \\ -0.96 & 0.06 & -0.30 & 0.16 \\ (0.36) & (0.61) & (0.21) & (0.47) \\ 0.02 & 0.54 & -0.48 & -0.50 \\ (0.38) & (0.58) & (0.23) & (0.48)\end{array}$

Income in dollars

0-3,000

$\begin{array}{cccc}1.24 & -0.12 & 0.08 & 0.48 \\ (0.46) & (0.58) & (0.26) & (0.45) \\ -0.24 & -0.43 & 0.03 & 0.94 \\ (0.36) & (0.53) & (0.20) & (0.43) \\ 0 & 0 & 0 & 0 \\ - & - & - & - \\ 0.20 & -0.25 & 0.08 & -0.61 \\ (0.33) & (0.65) & (0.18) & (0.63) \\ -0.50 & -0.39 & -0.07 & -1.53 \\ (0.38) & (0.91) & (0.91) & (1.04)\end{array}$

Wage in dollars per hour

$0-1.50$

\subsection{6}

$(0.84)$

6.74

(1.13)

$1.50-1.75$

$1.75-2.00$

$2.00-2.50$

$2.50-3.00$

3.00 and above
$-0.16$

(0.64)

5.63

$-0.18$

$(0.82)$

$(0.52)$

2.15

0

$(0.60)$

-

$-1.03$

(0.34)

0

$-1.61 \quad-3.71$

(0.36)

$\begin{array}{cc}0 & 0 \\ -0.24 & - \\ -0.33 \\ (0.20) & (0.39) \\ -0.29 & 0.62 \\ (0.21) & (0.57) \\ -0.47 & 0.17 \\ (0.25) & (0.82) \\ -0.39 & -0.70 \\ (0.38) & (1.07) \\ -1.32 & -0.44 \\ (0.69) & (1.43)\end{array}$


Table A-1 (continued)

\begin{tabular}{|c|c|c|c|c|}
\hline \multirow[b]{2}{*}{ Characteristic and value } & \multicolumn{2}{|c|}{ Men } & \multicolumn{2}{|c|}{ Women } \\
\hline & White & Black & White & Black \\
\hline \multicolumn{5}{|l|}{ City } \\
\hline Baltimore & $\begin{array}{r}-1.25 \\
(0.71)\end{array}$ & $\begin{array}{c}0.42 \\
(0.79)\end{array}$ & $\begin{array}{r}-0.58 \\
(0.39)\end{array}$ & $\begin{array}{r}-0.75 \\
(0.63)\end{array}$ \\
\hline Chicago & $\begin{array}{r}-1.70 \\
(0.43)\end{array}$ & $\begin{array}{c}-0.40 \\
(0.74)\end{array}$ & $\begin{array}{c}-0.11 \\
(0.25)\end{array}$ & $\begin{array}{r}-0.37 \\
(0.58)\end{array}$ \\
\hline Cleveland & $\begin{array}{r}-1.37 \\
(0.70)\end{array}$ & $\begin{array}{c}0.52 \\
(1.10)\end{array}$ & $\begin{array}{r}-0.29 \\
(0.42)\end{array}$ & $\begin{array}{c}1.56 \\
(0.95)\end{array}$ \\
\hline Detroit & $\begin{array}{c}-0.14 \\
(0.49)\end{array}$ & $\begin{array}{c}2.82 \\
(0.79)\end{array}$ & $\begin{array}{c}-0.17 \\
(0.28)\end{array}$ & $\begin{array}{c}1.35 \\
(0.60)\end{array}$ \\
\hline Houston & $\begin{array}{c}-0.89 \\
(0.76)\end{array}$ & $\begin{array}{c}-2.70 \\
(0.91)\end{array}$ & $\begin{array}{c}-0.44 \\
(0.45)\end{array}$ & $\begin{array}{r}-0.38 \\
(0.74)\end{array}$ \\
\hline Los Angeles & $\begin{array}{c}0.32 \\
(0.35)\end{array}$ & $\begin{array}{c}3.77 \\
(0.79)\end{array}$ & $\begin{array}{c}0.29 \\
(0.21)\end{array}$ & $\begin{array}{c}1.21 \\
(0.60)\end{array}$ \\
\hline New York & $\underline{0}$ & $\underline{0}$ & $\underline{0}$ & $\underline{0}$ \\
\hline Philadelphia & $\begin{array}{c}-1.08 \\
(0.46)\end{array}$ & $\begin{array}{c}0.21 \\
(0.82)\end{array}$ & $\begin{array}{c}-0.22 \\
(0.27)\end{array}$ & $\begin{array}{c}0.51 \\
(0.64)\end{array}$ \\
\hline Pittsburgh & $\begin{array}{r}-0.20 \\
(0.62)\end{array}$ & $\begin{array}{c}1.81 \\
(1.87)\end{array}$ & $\begin{array}{c}0.27 \\
(0.36)\end{array}$ & $\begin{array}{c}1.76 \\
(1.59)\end{array}$ \\
\hline St. Louis & $\begin{array}{c}-0.31 \\
(0.72)\end{array}$ & $\begin{array}{c}-0.46 \\
(1.10)\end{array}$ & $\begin{array}{c}-0.25 \\
(0.38)\end{array}$ & $\begin{array}{c}3.21 \\
(0.87)\end{array}$ \\
\hline San Francisco & $\begin{array}{c}0.69 \\
(0.43)\end{array}$ & $\begin{array}{c}5.39 \\
(0.98)\end{array}$ & $\begin{array}{c}0.43 \\
(0.25)\end{array}$ & $\begin{array}{c}1.35 \\
(0.80)\end{array}$ \\
\hline Washington, D.C. & $\begin{array}{r}-0.95 \\
(0.56)\end{array}$ & $\begin{array}{c}-0.44 \\
(0.70)\end{array}$ & $\begin{array}{c}-0.52 \\
(0.32)\end{array}$ & $\begin{array}{r}-0.30 \\
(0.52)\end{array}$ \\
\hline Standard error (in weeks) & 6.63 & 9.13 & 4.18 & 7.88 \\
\hline Number of observations & 3,433 & 2,361 & 4,042 & 2,721 \\
\hline
\end{tabular}

Source: Based on data from Survey of Economic Opportunity, conducted by U.S. Bureau of the Census, spring 1967. See appendix text for detailed information on the characteristics. The figures in parentheses are the standard errors. 


\section{Comments and Discussion}

R. A. Gordon: Robert Hall's paper is an important contribution to our understanding of why unemployment is as high as it is in the United States when we are close to full employment by conventional standards. His main conclusions seem to be that unemployment in the United States is relatively high at full employment not because large numbers of people remain continuously unemployed, but because large fractions of some groups in the labor force experience abnormally frequent changes of jobs with frequent periods of unemployment between jobs.

The relatively underprivileged groups, in his results, are blacks of both sexes and of virtually all ages; and white women of ages 25 and over. In general, I agree with this conclusion, but it is not the whole story. Let me focus on Table 5, "Comparison of Hypothetical Normal Rates of Unemployment and Actual Rates." The assumptions in the calculations are generally reasonable, but men and women should have been differentiated. Women over 25 , the group that has the unfavorable differential, are usually married, and they move frequently in and out of the labor force. Higher turnover rates would be expected for this group. The second point I would make is that this part of the study does not deal with the effect of differential unemployment on rates of participation in the labor force. Thus the participation rate in the prime-age group of males is significantly lower for blacks than for whites. Furthermore, there is significant nonreporting among black males. These elements constitute a kind of hidden unemployment.

The third point is that nothing is said about the time dimensions of the problem. As is pointed out in George Perry's paper, changes in the composition of the labor force over the last fifteen or twenty years make a 4 percent unemployment rate much more difficult to achieve and likely to 
generate greater inflationary consequences than was true formerly. Dispersion measures of unemployment rates by age and sex, like the ones Perry uses, show a cyclical pattern, but more important they reveal a dramatic rise in dispersion for any given overall unemployment rate over the last ten years or so. What may have been normal in 1950 or 1955 is probably not normal today.

Hall's paper does not take account of experience abroad. International comparisons highlight the extent to which frictional unemployment in the narrow sense- "normal" unemployment in Hall's term-is significantly higher in the United States than in most other countries. In Germany, a program called "Schlechtwettergeld" has reduced the seasonal unemployment in the construction trades that accounts for a significant component of frictional unemployment in the United States. Hall uses very high rates as normal frictional unemployment for youth. These rates do not occur in Europe, where young people coming out of school move fairly smoothly into either apprenticeship programs or regular jobs. The question of what frictional unemployment rate is normal is itself something that needs to be investigated.

The hypothetical normal unemployment rates by age, sex, and race in Hall's calculation imply an overall unemployment rate of 3.3 percent in 1969 , while the actual unemployment rate was 3.5 percent. Structural unemployment was not merely the difference of two-tenths of a percent, because the white prime-age male rate has been driven down below normal, creating job scarcities and tight markets. Thus 1969 was, in a way, the worst of both possible worlds-high structural unemployment or nonnecessary frictional unemployment for many groups at the same time that the labor market situation for prime-age white males was so tight as to drive up wages very rapidly.

The section on the differences among cities is interesting. The same permanence in unemployment differentials, however, also exists among other dimensions of the labor force-age, sex, color, as well as occupation, industry, and marital status. Maintained geographical differentials should therefore not be surprising. Although Hall may disagree, I see considerable similarity between his conclusions and the dual labor market hypothesis that has been advanced by Peter B. Doeringer and others. It is not essential to the dual labor market hypothesis that unemployment be related to income, as Hall implies in the final section of his paper. Rather, the unattractiveness of available jobs for blacks presents a trade-off between leisure and 
work for blacks that is different from that for white workers. The dual labor market hypothesis is that through discriminatory practices, some significant part of our labor force is deprived of an opportunity to try for attractive jobs that others can get rather easily. The result is that the deprived people leave the unattractive jobs frequently because they are unattractive. Instead of the standard notion of a queue, with blacks, for example, at the end of the queue, there are instead two lines. Whites get into one while blacks must get into the other. The black line is constantly re-forming, as blacks take unskilled jobs at a low wage rate, quit, are on the street awhile, come back when they need more money, and then quit again.

Charles Holt: I would like to reiterate Aaron Gordon's commendatory remarks. Hall has pulled together, with analytical and empirical insight, a lot of information that has previously been given too little attention by macroeconomists.

Hall's work is really more general than is suggested by his characterization of it as relevant only to a situation at full employment. In Woytinsky's analysis of unemployment data in the thirties, when the duration of unemployment was running up to five years, the same exponential shape of the distribution of duration of unemployment applied in those extreme situations. Far from being a rather specialized analysis, Hall's way of looking at things is useful over a broad range of unemployment rates. Nor should it be thought of as describing the economy at an equilibrium level of unemployment. As Hall notes, the level of unemployment we think of as full employment is not very critical in view of the amount of inflation the nation is willing to accept. It is not critical because, for a fairly wide range of assumptions about the tolerable rates of inflation, there is a corresponding fairly narrow range of unemployment rates. And the burden of the analysis is to focus on the fact that unemployment rates are very different for various demographic groups, whatever the aggregate unemployment rate is. A 3.8 percent unemployment target is associated with a 25 percent unemployment rate for black teenagers.

The basic analysis finds that the duration of an unemployment spell for an individual is not very long. Also, the data reveal that unemployment rates are drastically different for different groups. Together, these findings imply that differences in group unemployment rates should be explained by differences in their turnover rates-movements in and out of unemploy- 
ment. Work that Ralph Smith and I have been doing on the black-white unemployment rate shows that this is strikingly the case. The quit rate for blacks is roughly double that for whites; the layoff rate for blacks is double that of whites. Together these account for most of the unemployment differential.

The two components of turnover, voluntary quits and involuntary layoffs, respond in opposite directions to cyclical fluctuations. When unemployment falls, the quit rate rises, the layoff rate falls, and the turnover rate changes very little. When unemployment rises, the opposite happens. Thus the flow through the labor market over the cycle is roughly constant. The cyclical fluctuation in the level of unemployment therefore must be found in cyclical variations in the duration of unemployment. This in turn is attributable to changes in the stock of job vacancies.

Hall found relatively stable patterns of unemployment among cities. Over time, the tendency was for the unemployment rates in different cities to change by roughly the same proportions. Cities that had low unemployment rates had a decline of roughly the same proportion as cities that had high unemployment rates. If Hall had had industry or occupational data on unemployment, and had held these constant while comparing cities as he held constant the demographic composition of the work force, I think he would have been able to explain a large part of the differences among cities. Nevertheless, the persistent patterns he finds are not surprising.

This kind of persistent differential arises within demographic, occupational, or other classifications of the labor force as well. These are equilibrium relationships, not short-term deviations from equilibrium relationships. Hall found that high-unemployment cities tended to be high-wage cities. There are two factors influencing workers searching for jobs-the average wage rate and the probability of finding a job. It is not surprising to find a whole locus of points that are equally attractive, in terms of inducing mobility. Cities with high wages and high unemployment are as good as cities with low wages and low unemployment. The relationship between unemployment and wage rates fits better for males than for females because the prime wage earner is usually the husband. Where the husband goes for a job dominates where the family lives. The secondary workers in the family, the wives, go into whatever labor market they live in and do the best they can. Finding that stable line between the level of wages and level of unemployment does not, however, suggest that there is anything wrong with the adjustment processes of mobility. It simply means that when a 
city deviates from that line there are corrective processes that tend to bring it back to the line. The equilibrium is a line rather than a point.

Hall is properly critical of those who would use the search theory concepts to minimize the unemployment problem. The search theory now ought to be characterized as a search-turnover theory. If we had neither a search problem nor a turnover problem, then indeed we would have no unemployment problem.

Market segmentation has important implications for this turnover phenomenon. On one hand, there is an overall labor market that makes all unemployment rates rise and fall together, indicating the interaction of individual labor markets. On the other hand, very large differentials exist among the various demographic groups, indicating that there are very real barriers to the search or recruitment process, and differences in both the quality of the jobs and the rate of turnover persist. Studies by Robert E. Lipsey and G. C. Archibald, and some I have done, try to stress segmentation of the labor market, but the theory is not fully developed. The model of a compartmentalized labor market is more fully developed than the segmented model. More research needs to be done on the latter. But the significance of segmenting and the implications of its impact on different groups in the economy have been recognized by search theorists, if not by all those who use this way to interpret unemployment developments.

Hall refers to an irreducible minimum of frictional unemployment. There is no irreducible minimum. Aggregate demand can lower any level of unemployment if the amount of inflation that will occur is ignored. The idea of a frictional process that puts a fixed and rigid irreducible minimum on unemployment is not the right model, though a limit on the inflation rate we will tolerate does create a minimum for policy purposes.

Limitations to the normal upgrading process for various demographic groups are stressed heavily in this paper. Guthrie has done a study that relates the speed of the upgrading process for blacks to the level of unemployment. He predicts that if past rates of upgrading are sustained and if the unemployment rate is maintained at $3 \frac{1}{2} 2$ percent, it will take twenty-five years before blacks and whites have essentially equal incomes. If the unemployment rate is maintained at $4 \frac{1}{2}$ percent, the time to equality is doubled. ${ }^{1}$ Pavis has done work that indicates that eliminating the unem-

1. Harold W. Guthrie, "The Prospect of Equality of Incomes between White and Black Families under Varying Rates of Unemployment," Journal of Human Resources, Vol. 5 (Fall 1970), pp. 431-46. 
ployment rate differential between blacks and whites would raise black incomes by approximately $\$ 1 \frac{1}{2}$ billion. If, in addition, the average wage level of blacks is raised to that of whites, black income would rise by approximately $\$ 14$ billion. $^{2}$ So the upgrading process in labor markets is terribly important and it interacts with the unemployment-inflation problem. A relatively high level of vacancies speeds upgrading and lowers unemployment, but increases inflation.

One thing that is a bit surprising is Hall's minor reference to vacancies, a variable that is jointly determined and is the link to the inflationary process. In addition, the level of vacancies influences turnover rates and duration of unemployment. Barely mentioning vacancies is somewhat like analyzing the quantity of money without considering the interest rate.

In conclusion I would like to say again that Hall's paper is a very useful contribution to our understanding of the unemployment problem, an understanding that is essential for our balancing of inflation against unemployment.

Robert Hall: In answer to Gordon's remarks, I did not separate the men from the women in constructing a theoretical unemployment rate because that would imply a very basic assumption that the pattern of the way women are treated is somehow right. I am not convinced of that. There is no presumption that it ought to be women who take care of children. On another point, there is a sense in which permanent geographical differentials are a different matter from permanent age and race differentials. We know that blacks are treated worse in labor markets than whites. But there is no equivalent sense in which Chicago is very different from Los Angeles. Yet the difference between Chicago and Los Angeles certainly shows up in the data, and that is why I chose to look at the geographical dimension.

Turning to some of Holt's remarks, I could make an adjustment for industry composition to see if it explains some of the city differences in unemployment. I am a little hesitant to do that in a mechanical way, such as by putting in industry dummies. If this washed out the city differencesand I am not convinced it would-I would want to go deeper into the source of the industry differentials.

2. Rhona L. Pavis, "Towards the Equalization of Income and Occupational Distribution of Blacks and Whites and Males and Females," Working Papers 113-27 (Urban Institute, Nov. 28, 1969; processed). 
On the question of whether there is an irreducible minimum to the unemployment rate, I believe Holt's thinking is based on the assumption that the quit rate plus the layoff rate is constant. In a really tight labor market, the quit rate could rise so much that even though the layoff rate was virtually zero, unemployment might start going up again. But I am not asserting that there is an irreducible minimum; it is not something I go into here.

\section{General Discussion}

Franco Modigliani felt that there was an irreducible minimum rate of employment, because regardless of how many vacancies there are, it takes some time for a person to find a job. William Fellner speculated that the frequency of unemployment might increase initially for disadvantaged groups who are becoming less disadvantaged, because the relations between the employees and employers are more experimental as they are tried in new kinds of jobs. This would have optimistic implications for the future as the transition period ended. William Poole pointed out that the lifetime wage profile Hall showed, which was quite flat for the disadvantaged, was a cross section at a moment of time. He thought that this might reflect progress being made by these disadvantaged groups rather than a lack of progression in earnings over an individual's lifetime. Older people are caught in low-wage, dead-end jobs as a result of the more severe discrimination that existed when they started work, while younger workers are getting better jobs and will show progress during their lifetimes. For each type of skill, there could be a steady progression of wages through life, but at the present time, the distribution of people in occupations is very different for various age groups among the disadvantaged. Thomas Juster pointed out that there is bias in the kind of follow-up survey Hall reports on. The survey interviewed individuals who had been listed as out of the labor force. The bias comes because those who had been listed as unemployed were not resurveyed to discover how many should have been listed as out of the labor force. Juster also objected to using the same hypothetical unemployment rate for females and males if the purpose is to judge whether women are discriminated against. Many women are out of the labor force when their children are young. When they return to the labor force they are like 
new entrants in terms of their treatment by typical employers and should be given the hypothetical values assigned to new entrants. The distribution by age of those looking for first jobs and subsequent jobs is clearly affected by schooling status. If the hypothetical unemployment rate took account of educational status, better patterns by age, race, and sex, could be developed. If discrimination against blacks and women still showed up, Juster would find the results that much more persuasive. 